\title{
Cardiac rhythm in hypertension assessed through 24 hour ambulatory electrocardiographic monitoring Effects of load manipulation with atenolol, verapamil, and nifedipine
}

\author{
ALESSANDRO LOALDI, MAURO PEPI, PIER G AGOSTONI, CESARE FIORENTINI, \\ SERGIO GRAZI, PAOLO DELLA BELLA, MAURIZIO D GUAZZI \\ From Cattedra di Cardiologia, Istituto Ricerche Cardiovascolari "G Sisini", Fondazione "Italo Monzino", Centro \\ Ricerche Cardiovascolari del Consiglio Nazionale delle Ricerche, University of Milan, Milan, Italy
}

SUMMARY In systemic hypertension left ventricular wall stress (afterload) is reduced and function enhanced, compared with normal, in the presence of concentric hypertrophy; the opposite occurs when hypertrophy is combined with dilatation. In this study we tested the hypothesis that cardiac rhythm may be related, in part, to the interacting variables: left ventricular structure, afterload, and function.

Eighty-five primary hypertensives were divided into three groups: group 1 ( 24 cases with normal sized heart), group 2 ( 33 cases with concentric hypertrophy), and group 3 ( 28 cases with hypertrophy and dilatation). Cardiac rhythm, through 24-hour ambulatory electrocardiographic monitoring, and end-systolic left ventricular circumferential wall stress were investigated before and after seven days of treatment with atenolol, verapamil, and nifedipine in groups 1 and 2, and with the two calcium antagonists in group 3.

Atrial and ventricular extrasystoles were recorded in 75 to $100 \%$ of the subjects in the control group (13 normotensives) and in the hypertensive groups. Average 24 hour atrial ventricular extrasystoles in group 1, and ventricular extrasystoles in group 2, were similar to normal before treatment and were not affected by drugs; changes in circumferential wall stress with treatment were comparable. In group 2 the number of atrial extrasystoles in 24 hours was significantly higher than in all the other groups. They were not influenced by changes in wall stress, and were interpreted as related to the atrial "booster pump" action in the presence of concentric hypertrophy. In group 3 a great number of ventricular extrasystoles was associated with the highest baseline left ventricular afterload; circumferential wall stress and ventricular extrasystoles were poorly affected by verapamil, while the remarkable circumferential wall stress reduction caused by nifedipine was paralleled by an obvious decrease in ventricular extrasystoles.

These data support the possibility that in systemic hypertension a relation exists between cardiac structure, load, and rhythm, and that ventricular arrhythmias may benefit from effective left ventricular unloading.

Although the pathophysiology of the hypertensive heart and the influence of therapy have been investigated extensively over the years, cardiac rhythm in high blood pressure has remained almost entirely neglected.

Accepted for publication 12 April 1983
In the natural history of high blood pressure the condition of the heart is not static, but is subject to a progression of interrelated anatomical and functional changes. ${ }^{1-3}$ Schematically, three successive structural steps may be outlined: normal heart, concentric hypertrophy, and hypertrophy associated with left ventricular cavity enlargement. Because of the differ- 
ent influences that these three conditions exert on ventricular afterload and function, ${ }^{4-8}$ it is conceivable that cardiac rhythm in hypertension may be related to the structure and, through this, to the functional state of the heart. The findings of Messerli and collaborators ${ }^{9}$ are in keeping with this interpretation, for they reported an increased incidence of ventricular premature contractions in hypertensive patients with left ventricular hypertrophy, compared with patients having similar levels of pressure with a structurally normal heart. On this basis, it also seems reasonable to suppose that the influence of antihypertensives on the rhythm of the heart may be in part related to the effects on ventricular afterload and function.

To verify these hypotheses, cardiac rhythm was studied through 24 hour ambulatory electrocardiographic monitoring in a hypertensive population before and after manipulation of afterload with atenolol, verapamil, and nifedipine. The beta blocker, atenolol, was chosen as representative of a class of compounds having a predominant place in the treatment of high blood pressure; the calcium antagonists, verapamil and nifedipine, were chosen not only in view of their recent and expanding use in the therapeutic management of hypertension, ${ }^{10}$ but also because their potent vasodilating action can be expected to unload the heart.

\section{Subjects and methods}

Patients chosen for this study were aged 65 years or less, and suffered from primary hypertension of variable duration and severity; they were free of myocardial infarction, angina pectoris, valvular or primary myocardial disease, history, symptoms, and clinical signs referable to heart failure, stroke, or recurrent transient cerebral ischemia, any degree of atrioventricular block or bundle-branch block, severe renal or hepatic insufficiency; and were judged clinically suitable for placebo treatment. One hundred and three patients met these criteria; 18, however, were excluded because of an inability to record a technically satisfactory left ventricular echocardiogram (11 cases), or the presence of segmental left ventricular contraction abnormalities (four cases), or disproportionate septal thickening (septal to posterior left ventricular free wall thickness ratio of 1.3 or greater) (three cases). The final study group comprised 85 patients, 62 men and 23 women, ranging in age from 24 to 63 years (mean 38). Twenty-six patients were untreated and 59 were receiving antihypertensives on admission. None had been given digitalis or antiarrhythmic drugs at any time in the past.

Age matched subjects in the hospital without circulatory disorders or medication that could interfere with their cardiovascular function were also studied as controls ( 13 subjects). They were identified as group 0.

The 85 hypertensive patients were classified in three groups according to the following echocardiographic criteria: group 1, 24 cases in whom septal and posterior wall thickness and end-diastolic left ventricular minor axis were within 1 SD of the normal control values (control values were derived from subjects in group 0 and from 18 normal subjects ${ }^{5}$ who were investigated in a previous study); group 2, 33 patients with normal or slightly reduced left ventricular end-diastolic minor axis and both septal and posterior wall thickness exceeding mean plus 1 SD of control; in group 3 (28 cases) wall thickness was within the same range as in group 2, but end-diastolic minor axis exceeded the mean plus $1 \mathrm{SD}$ for this group. These criteria defined the structural characteristics of the heart: normal sized heart (group 1), concentric hypertrophy (group 2), and hypertrophy associated with left ventricular cavity enlargement (group 3).

\section{STUDY DESIGN}

Patients were either untreated or had interrupted any antihypertensive medication (including diuretic drugs) two weeks before the baseline 24 hour monitoring. In those who were taking beta blockers, withdrawal from treatment took place over three to four days. During the first week the routine laboratory work was performed, and secondary causes of high blood pressure were ruled out. Then, wall thickness and diastolic dimension of the left ventricle were evaluated by ultrasound, and patients were classified accordingly. Cases in groups 1 and 2 were separated randomly into three subgroups to be treated with atenolol $(100 \mathrm{mg} /$ day $)$, verapamil $(120 \mathrm{mg}$ tid $)$, or nifedipine (10 $\mathrm{mg}$ qid). We decided not to test the beta blocker atenolol in group 3, as we were concerned about possible deterioration in cardiac function in the presence of left ventricular enlargement. Group 3 patients, therefore, were randomly assigned to one of two subgroups, which received verapamil or nifedipine.

During the second week in hospital a placebo was administered in capsules or pills identical in shape and colour to the active compound to be given; when necessary, oral potassium was supplemented in order to bring the serum potassium concentration up to normal and prevent the influence of hypokalaemia on the activity of the heart. At the end of this run-in period, while on placebo, all subjects underwent echocardiographic assessment of left ventricular wall stress, and two consecutive 24 hour ambulatory electrocardiograms. Then patients received active drugs for the subsequent seven days, at the end of which 24 
hour electrocardiographic monitoring and ultrasound procedures (two hours after a drug dose) were repeated. Three patients in group 3 received nifedipine after verapamil, and the 24 hour electrocardiographic monitoring and echocardiography were repeated again after a seven day treatment.

\section{ELECTROCARDIOGRAPHIC AMBULATORY MONITORING}

All 24 hour electrocardiographic recordings were performed using Avionics, Model 1445/B, two channel recorders. Tape recordings were analysed by the same personnel using a Del Mar Avionics Trendsetter, Model DCG VII Dynamic Electrocardioscanner. With this method, the electrocardiogram was played into a computer and the following data were quantified for each patient: the total number of heart beats, the highest and the lowest heart rate/min, and the total number of any atrial extrasystoles, of any ventricular extrasystoles, and of any "complex" ventricular extrasystoles; under the term "complex" we included bigeminy, couplets, salvoes of unsustained ventricular tachycardia (defined as three or more ventricular depolarisations occurring in succession at a rate between 100 and 200 cycles/min).

For each patient all recordings were started at the same time of the day. In order to maintain a similar daily life style, all the subjects were admitted to hospital for the entire duration of the study; they were ambulatory and encouraged to be active. To ensure the reproducibility of the baseline cardiac rhythm, patients underwent two consecutive 24 hour electrocardiographic recordings while receiving placebo. The upper limit of variability between the two measurements was $2 \%$ for the total number of beats, $4 \%$ for the highest and lowest rate/min, and $10 \%$ for the number of arrhythmias. The averages were taken as the representative values for each patient.

\section{ULTRASOUND MEASUREMENTS}

Echocardiographic studies were carried out with a Hewlett-Packard ultrasound unit, model 77020 A, interfaced with a Sony videotape recorder. After positioning the cursor at the high chordal level, simultaneous $M$-mode and cross-sectional recordings were obtained from the parasternal position in both long and short axis views of the left ventricle. All views were evaluated by two observers (AL and MP) for evidence of any regional wall motion abnormality and to make sure that the contractile state was uniform. Measurements were performed by these two investigators without knowledge of the patients' clinical data. Left ventricular end-diastolic dimension was measured at the peak of the $\mathbf{R}$ wave of the electrocardiogram; end-systolic dimension was measured as the smallest vertical distance between the septum and posterior wall. Septal and posterior wall thicknesses were measured using the leading edge to leading edge method. End-diastolic measurements of wall thickness were made at the onset of the QRS complex in the electrocardiogram. End-systolic septal thickness was measured at the point of maximal posterior septal motion, and end-systolic posterior wall thickness at the point of maximal anterior motion. Data were analysed as the mean of three to five consecutive cycles. Whenever discordance exceeded $1 \mathrm{~mm}$ between $\mathbf{M}$-mode and cross-sectional measurements, the cross sectional data were used as quality control checks on the accuracy of the M-mode calculations. The loss of endocardial reflectance may contribute to underestimating wall thickness, without the additional use of cross-sectional imaging. ${ }^{1112}$ From echocardiographic measurements end-systolic left ventricular circumferential wall stress was calculated, according to the formula of Grossman and coworkers ${ }^{13}$ modified by Reichek et al., ${ }^{14}$ as follows:

$$
\text { es CWS }=\frac{0.334 \times \text { Ps } / \text { LVIDs }}{\text { PWTs }\left(1+\frac{\text { PWTs }}{\text { LVIDs }}\right)}
$$

where es CWS is end-systolic circumferential wall stress, LVIDs and PWTs are left ventricular minor dimension $(\mathrm{cm})$ and posterior wall thickness $(\mathrm{cm})$ at end-systole; Ps is systolic cuff arterial pressure. Pressure was measured by an independent observer three times consecutively (with five minute intervals between each measurement) with the patient at resst, after 15 minutes' recumbency. Readings were averaged to obtain a more accurate measurement. Values of wall stress were taken as reflecting left ventricular afterload at the end of the systole.

\section{STATISTICAL METHODS}

The differences between normal and hypertensive subjects, between the three hypertensive groups, and between the untreated and treated condition were evaluated through the analysis of variance. Statistical evaluations were performed through a Kontron computer, model Cardio 80.

\section{Results}

Age was similar in the hypertensive groups 2 and 3 and not significantly different from controls; patients in group 1 were slightly, but significantly, younger. Supine mean arterial pressure taken at the end of the run-in period was comparable in groups 2 and 3 , and in both of these significantly higher than in group 1 . These data are summarised in Table 1.

Bars in Fig. 1 indicate the averages of the total number of heart beats and the highest and the lowest heart rate per minute recorded during the baseline 24 
Table 1 Age, mean arterial pressure, and echocardiographic measurements (averages and SD)

\begin{tabular}{|c|c|c|c|c|c|c|c|c|}
\hline \multirow[b]{2}{*}{$\begin{array}{l}\text { Age }(\mathrm{y}) \\
\text { Mean arterial pressure (mmHg) } \\
\text { Left ventricular end-diastolic minor axis }(\mathrm{mm}) \\
\text { Left ventricular posterior wall thickness }(\mathrm{mm}) \\
\text { Left ventricular septal wall thickness }(\mathrm{mm})\end{array}$} & \multicolumn{2}{|c|}{ Group 0} & \multicolumn{2}{|c|}{ Group 1} & \multicolumn{2}{|c|}{ Group 2} & \multicolumn{2}{|l|}{ Group 3} \\
\hline & $\begin{array}{r}42 \\
102 \\
47.5 \\
9.1 \\
9.2\end{array}$ & $\begin{array}{l}(6) \\
(4) \\
(1.5) \\
(0.9) \\
(0.7)\end{array}$ & $\begin{array}{r}34^{\star} \\
124^{\star} \\
46.2 \\
9.6 \\
9.7\end{array}$ & $\begin{array}{l}(3) \\
(9) \\
(2 \cdot 2) \\
(0.8) \\
(0.6)\end{array}$ & $\begin{array}{c}43 \\
133^{\star} t \\
43 \cdot 6^{\star} \\
13 \cdot 7^{\star} \\
13 \cdot 9^{\star}\end{array}$ & $\begin{array}{l}(5) \\
(16) \\
(1 \cdot 7) \\
(1 \cdot 2) \\
(1 \cdot 1)\end{array}$ & $\begin{array}{l}45 \\
131^{\star} \dagger \\
549^{\star} \dagger \\
13^{\star} \\
13 \cdot 3^{\star}\end{array}$ & $\begin{array}{l}(7) \\
(12) \\
(4.8) \\
(1.5) \\
(1.2)\end{array}$ \\
\hline
\end{tabular}

$\star$ Significant differences from control subjects $(p<0.01)$.

†Significant differences from hypertensive group $2(p<0.01)$.

Table 2 Types, prevalence (\%), and frequency of cardiac arrhythmias during 24 hours in untreated patients in normotensive and hypertensive groups

\begin{tabular}{|c|c|c|c|c|c|c|c|c|c|c|c|c|c|c|c|c|c|c|c|c|}
\hline \multirow[t]{2}{*}{$\begin{array}{l}\text { Arrhythmias } \\
\text { in } 24 \text { hours }\end{array}$} & \multicolumn{4}{|c|}{$\begin{array}{l}\text { Atrial } \\
\text { premature contractions }\end{array}$} & \multicolumn{4}{|c|}{$\begin{array}{l}\text { Ventricular } \\
\text { premature contractions }\end{array}$} & \multicolumn{4}{|c|}{ Bigeminy } & \multicolumn{4}{|c|}{ Couplets } & \multicolumn{4}{|c|}{$\begin{array}{l}\text { Salooes of } \\
\text { ventricular tachycardia }\end{array}$} \\
\hline & $G_{0}$ & $\begin{array}{r}\text { roups } \\
1\end{array}$ & 2 & 3 & 0 & 1 & 2 & 3 & 0 & 1 & 2 & 3 & 0 & 1 & 2 & 3 & 0 & 1 & 2 & 3 \\
\hline $\begin{array}{c}251-300 \\
201-250 \\
151-200 \\
101-150 \\
51-100 \\
11-50 \\
1-10 \\
0\end{array}$ & $\begin{array}{l}6 \\
7\end{array}$ & $\begin{array}{l}12 \\
12\end{array}$ & $\begin{array}{l}3 \\
2 \\
5 \\
9 \\
7 \\
6 \\
1\end{array}$ & $\begin{array}{r}2 \\
12 \\
9 \\
4 \\
1\end{array}$ & $\begin{array}{l}3 \\
6 \\
4\end{array}$ & $\begin{array}{r}4 \\
14 \\
6\end{array}$ & $\begin{array}{r}6 \\
20 \\
8\end{array}$ & $\begin{array}{l}8 \\
6 \\
3 \\
7 \\
3 \\
1 \\
0\end{array}$ & $\begin{array}{r}1 \\
12\end{array}$ & 21 & $\begin{array}{r}5 \\
28\end{array}$ & $\begin{array}{r}3 \\
5 \\
20\end{array}$ & 13 & 24 & 33 & $\begin{array}{r}1 \\
5 \\
22\end{array}$ & 13 & 24 & 33 & $\begin{array}{r}6 \\
22\end{array}$ \\
\hline Prevalence & 100 & 100 & 100 & 100 & 75 & 75 & 75 & 100 & 8 & 13 & 17 & 28 & 0 & 0 & 0 & 22 & 0 & 0 & $\overline{0}$ & 22 \\
\hline
\end{tabular}
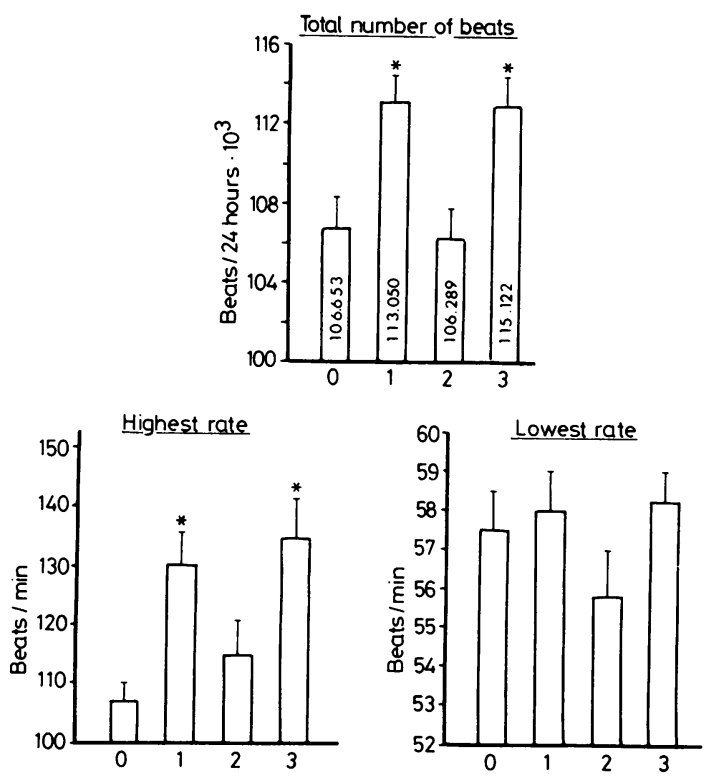

Fig. 1 Averages (SD) of the total number of heart beats and of the highest and lowest rate/min recorded during 24 hours in the control (group 0) and in the three hypertensive groups (groups 1, 2 , and 3). *Significant differences from group $0(p<0.01)$.

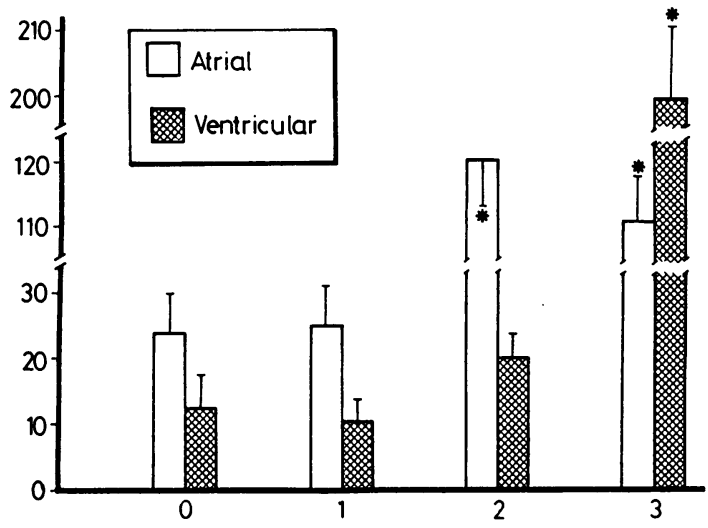

Fig. 2 Averages (SD) of atrial and ventricular extrasystoles recorded during baseline 24 hours in normal and hypertensive groups. * Significant differences from group $0(p<0.01)$.

hours in the control and in the three hypertensive groups. The number of beats per 24 hours was significantly much higher than normal in groups 1 and 3 , and this difference was associated with higher averages of the maximal and minimal heart rates per minute recorded in the 24 hours. In group 2 these values were similar to normal. 

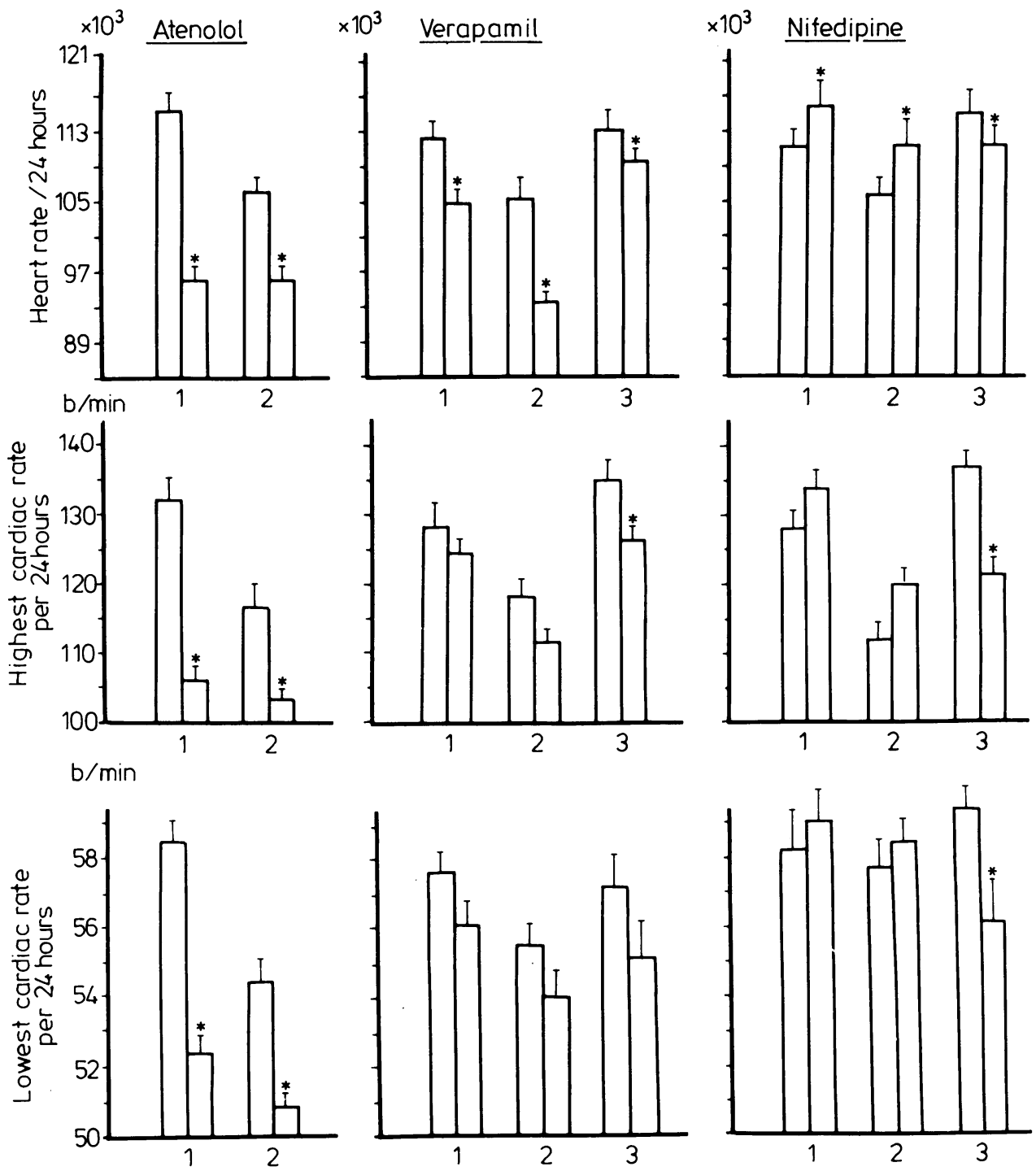

Fig. 3 Averages (SD) of the total number of heart beats (upper part), of the highest (middle part), and of the lowest (lower part) cardiac rate /min recorded during 24 hours in the hypertensive groups in the baseline (left bar of each pair) and after seven days of treatment (right bar of each pair) with, respectively, atenolol, verapamil, and nifedipine. *Significant differences from the pretreatment condition $(p<0.01)$.

Types, prevalence, and frequency of cardiac arrhythmias recorded in the control subjects and in the three hypertensive groups at the end of the run-in are summarised in Table 2 . It is shown that atrial and ventricular extrasystoles were recorded in the majority of both normotensive and hypertensive subjects (prevalence ranging from 75 to $100 \%$ of cases); the frequency of atrial extrasystoles, however, was definitely higher in group 2 and that of ventricular extrasystoles higher in group 3, as compared with the other groups.

Prevalence and frequency of bigeminy were low and were similar in all the groups. Couplets and short runs (less than eight successive ventricular beats in any case) of ventricular tachycardia were recorded only in group 3 , in $22 \%$ of the patients. The frequency of the salvoes of ventricular tachycardia did not exceed 10 in the 24 hours. 

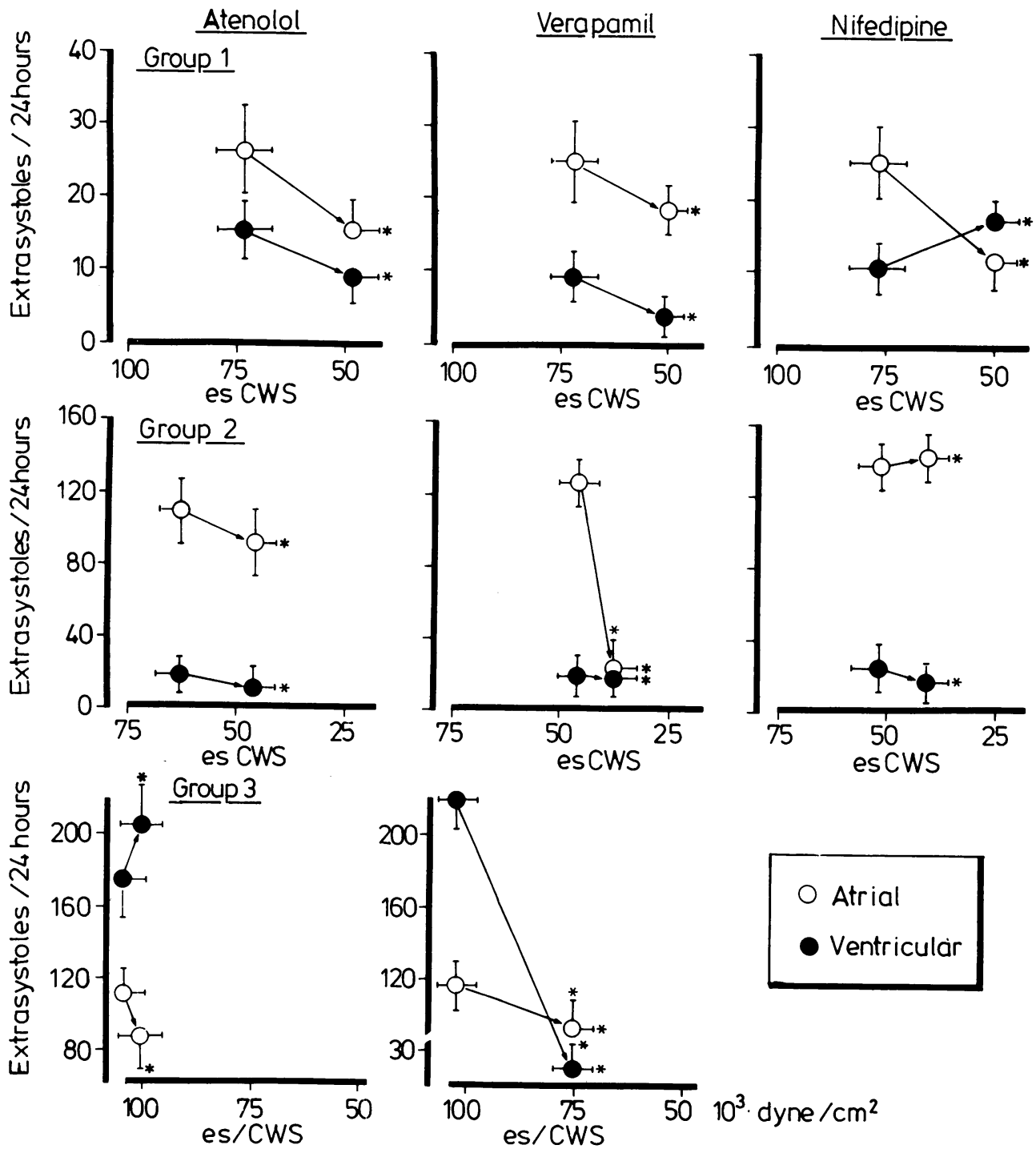

Fig. 4 Averages (SD) of atrial (open circles) and ventricular (solid circles) extrasystoles per 24 hours in the baseline and after atenolol, verapamil, and nifedipine, and corresponding values of left ventricular end-systolic circumferential wall stress (es CWS). *Significant differences from baseline $(p<0.01)$.

Fig. 2 shows the averages of atrial and ventricular extrasystoles in 24 hours recorded in the baseline in normal and hypertensive groups. In the control and group 1 patients averages of either type of arrhythmia were comparable. In group 2 the number of ventricular extrasystoles was also similar to normal, while that of atrial extrasystoles was largely and significantly higher than in the control and hypertensive group 1 subjects. A number of ventricular extrasystoles strongly differentiated group 3 from the other groups; the number of atrial extrasystoles was also larger than normal in this group.

As shown in Fig. 3, atenolol in groups 1 and 2 and verapamil in groups 1,2 , and 3 invariably.reduced the number of beats over the 24 hours. The effects of nifedipine, however, were not uniform, beat rate in 24 hours being augmented in groups 1 and 2 , and reduced in group 3. Both maximal and minimal beat 
Table 3 End-systolic left ventricular circumferential wall stress (es CWS) and ventricular extrasystoles in group 3 patients treated with both verapamil and nifedipine

\begin{tabular}{|c|c|c|c|}
\hline Patients & & $\begin{array}{l}\text { esCWVS } \\
\left(10^{3} . \text { dyn } \mathrm{cm}^{2}\right)\end{array}$ & $\begin{array}{l}\text { Ventricular } \\
\text { extrasystoles } \\
(24 h)\end{array}$ \\
\hline 1 & $\begin{array}{l}\text { Placebo } \\
\text { Verapamil } \\
\text { Nifedipine }\end{array}$ & $\begin{array}{c}121 \\
148 \\
66.4\end{array}$ & $\begin{array}{r}130 \\
250 \\
25\end{array}$ \\
\hline 2 & $\begin{array}{l}\text { Placebo } \\
\text { Verapamil } \\
\text { Nifedipine }\end{array}$ & $\begin{array}{l}131 \\
144 \\
111\end{array}$ & $\begin{array}{r}51 \\
130 \\
16\end{array}$ \\
\hline 3 & $\begin{array}{l}\text { Placebo } \\
\text { Verapamil } \\
\text { Nifedipine }\end{array}$ & $\begin{array}{l}83.6 \\
97 \\
58.7\end{array}$ & $\begin{array}{r}22 \\
43 \\
6\end{array}$ \\
\hline
\end{tabular}

rate after treatment varied in parallel with the changes in the number of beats every 24 hours.

Fig. 4 illustrates the averages of atrial and ventricular extrasystoles recorded during the 24 hour continuous monitoring in the pre- and post-treatment periods, and the corresponding values of end-systolic circumferential wall stress. Reduction in wall stress was significant in groups 1 and 2 after any of the three compounds. In group 3 the decrease in wall stress was slight and not statistically significant in patients receiving verapamil, and this poor effect contrasted with the great unloading efficacy of nifedipine in patients in the same group. Atrial and ventricular extrasystoles were invariably reduced, respectively, in group 2 subjects treated with verapamil, and in group 3 patients receiving nifedipine. Changes from control were statistically significant.

Data in Table 3 provide further evidence of the different unloading efficacy of the two calcium antagonists on the dilated hypertensive left ventricle. In three patients in group 3 who received placebo, verapamil, and nifedipine in sequence, wall stress was unchanged or augmented with verapamil and greatly reduced with nifedipine. Ventricular extrasystoles varied in parallel with wall stress.

\section{Discussion}

The validity of the non-invasive methods used to determine left ventricular end-systolic wall stress has been proved. ${ }^{14-16}$ Segmental variations in myocardial performance, which are important limitations to these methods, ${ }^{1718}$ were carefully avoided in this study. It is considered that the calculated index reliably reflected the stress of the ventricular wall at the end of the systolic period. End-systolic stress reflects the maximal level of the instantaneous myocardial force for the existing instantaneous myocardial length or volume during the ejection phase. ${ }^{17}$ Thus, endsystolic stress is literally the afterload that limits ejection, and may have a special conceptual value as an afterload marker.

Several studies have validly established that a close relation exists between cardiac load and function in high blood pressure, 45 and that left ventricular afterload is an important determinant of the performance of the left ${ }^{19}$ and also of the right side ${ }^{6}$ of the human hypertensive heart. In the present study systolic cardiac function was maintained in group 1, possibly enhanced in group 2,45 and depressed in group 3.19 Findings on the rhythm of the heart will be discussed within the framework of cardiac afterload and function, with the possible additional intervention of neural or humoral factors.

It is likely that admittance to hospital may have reduced individual differences in cardiac rhythm related to life style. That group differences in the 24 hour number of beats reflected a distinct feature is supported by the observation that the highest and the lowest rates per minute varied from group to group in parallel with the total beats. The raised heart rate in 24 hours in group 1 might be related to younger age or to hyperdynamic activity of the heart, such as that characterising the early phase of essential hypertension. ${ }^{20}$ In group 3, tachycardia might simply reflect a mechanism of compensation for the raised circulatory load and the impaired performance of the heart. In contrast, a normal or enhanced cardiac performance in group 2 may be the reason why the chronotropic activity of the heart was maintained within normal limits.

Atenolol in groups 1 and 2 brought the heart rate in 24 hours down to almost equal levels. The fact that reduction was $17 \%$ in the former and $11 \%$ in the latter suggests that the increased heart rate in the untreated group 1 was in some way related to beta adrenergic receptor overstimulation. Verapamil also showed a negative chronotropic action, which contrasts with what one could expect as a consequence of the vasodilating action. A negative effect on cardiac pacemaker activity,,$^{21} 22$ or an influence of verapamil on the calcium dependent transmitter release from the post-ganglionic sympathetic endings ${ }^{23}$ may be offered as explanations for this discrepancy. Among the subjects who received nifedipine, the heart rate per 24 hours was augmented in groups 1 and 2 and reduced in group 3. The earlier part of the hypotensive response to a single oral dose of nifedipine is generally associated with an increase in heart rate ${ }^{24}$ that lasts for about an hour; in those patients taking four doses of nifedipine a day this may result in a significant increase of the number of beats recorded in the 24 hours. If the increased heart rate in the baseline in group 3 really reflected a mechanism of compensation 
for the raised afterload and the impaired performance, reduction in heart rate after nifedipine might be interpreted as a consequence of the decreased load and the improved cardiac performance in these patients.

In group 1 the beta receptor blocker and the two calcium antagonists showed a similar ventricular unloading efficacy and did not influence arrhythmias significantly. In group 2 the number of vertricular extrasystoles in the 24 hours duplicated those in group 1 and control subjects, while the average number of atrial premature depolarisations was impressively increased. If the normal total number of beats and maximal and minimal heart rates are interpreted as reflecting normal adrenergic activity in this group, then neural factors could be ruled out as responsible for atrial extrasystoles. In keeping with this interpretation is that atenolol did not abolish arrhythmias. Tarazi et al. ${ }^{25}$ described electrocardiographic left atrial abnormalities in hypertension, which were later supported by clinicophysiological correlation studies of heart disease in high blood pressure. ${ }^{3}$ On the other hand, the increased filling pressure of both ventricles found by Olivari et al., ${ }^{6}$ and the decrease of the left atrial emptying index reported in such cases by Dreslinski and collaborators ${ }^{8}$ suggest that ventricular diastolic compliance is abnormal in hypertensive concentric left ventricular hypertrophy. It might be speculated that the exaggerated "booster bump" action assumed by the atria to keep ventricular filling normal is somehow related to the atrial premature depolarisations detected in group 2 . While atenolol, verapamil, and nifedipine unloaded the left ventricle to a similar extent, atrial extrasystoles were reduced significantly only in the verapamil treated patients. This makes a relation between left ventricular afterload and atrial premature depolarisations unlikely, and suggests an influence of the drug on the ventricular diastolic properties or on the cardiac pacemaker activity.

In group 3 cardiac rhythm was disturbed predominantly by ventricular premature depolarisations and, in $28 \%$ of the cases, by "complex" ventricular extrasystoles. In the baseline this pattern was associated with the highest level of end-systolic left ventricular afterload. Differences in the responses to the two calcium antagonists in this group were twofold and involved both the ventricular unloading and the antiarrhythmic effect. Reduction in end-systolic wall stress after verapamil was not statistically significant; in contrast, the efficacy of nifedipine on ventricular wall stress was prominent. The number of ventricular extrasystoles in 24 hours was much reduced (from 223 to 13) in the patients treated with nifedipine and somewhat enhanced (from 177 to 206) in those who received verapamil. Couplets and salvoes of ventricular tachycardia were still seen in three cases of the latter and in one case of the former population. A short lasting period of second degree atrioventricular block was recorded during the night in two of the patients in this group who were receiving verapamil. The divergent response of ventricular extrasystoles to the two calcium antagonists is not really explained in terms of antiarrhythmic properties, since nifedipine seems to be devoid of such properties. ${ }^{26}$ On the basis of the relation that seems to exist between the effectiveness on ventricular afterload and that on arrhythmias, it is tempting to interpret the excessive contractile effort of the left ventricle as one of the elicitors of ventricular extrasystoles, and to ascribe to a potent unloading effect the antiarrhythmic response to nifedipine. The less pronounced efficacy on afterload of verapamil compared with nifedipine can possibly be referred to a lower vasodilating and impedance reducing potency, and to the intrinsic depressant effect of the compound on the myocardium. This effect is entirely offset when the baseline function of the heart is well preserved, but becomes apparent when the function is impaired. ${ }^{27}$

Clinical implications of these data may be that: (a) echocardiography can provide useful information regarding choice of antihypertensive drug treatment in relation to the function, as well as to the rhythm of the heart; (b) the cardiac rhythm in hypertension may present a clinical problem only in the presence of left ventricular enlargement; (c) a favourable influence on ventricular arrhythmias is an additional reason for considering effective left ventricular unloading compounds as best suited for treating hypertension in the presence of cardiac dilatation. These results also suggest that the three drugs investigated might be indicated in specific groups of patients and reinforce the concept that treatment of hypertension should be based on individual considerations; an accurate evaluation of the heart can provide guidelines for more appropriate treatment.

\section{References}

1 Freis ED. Hemodynamics of hypertension. Physiol Rev 1960; 40: 27-54.

2 Cohn JN, Limas CJ, Guiha NH. Hypertension and the heart. Arch Intern Med 1974; 133: 969-79.

3 Frohlich ED, Tarazi RC, Dustan HP. Clinicalphysiological correlations in the development of hypertensive heart disease. Circulation 1971; 44: 446-55.

4 Karliner JS, Williams D, Gorwit J, Crawford MH, O'Rourke RA. Left ventricular performance in patients with left ventricular hypertrophy caused by systemic arterial hypertension. Br Heart f 1977; 39: 1239-45.

5 Fiorentini C, Polese A, Olivari MT, Guazzi MD. Cardiac performance in hypertension re-evaluated through a combined haemodynamic ultrasonic method. Br Heart $\mathcal{F}$ 1980; 43: 344-50. 
6 Olivari MT, Fiorentini C, Polese A, Guazzi MD. Pulmonary hemodynamics and right ventricular function in hypertension. Circulation 1978; 57: 1185-90.

7 Hanrath P, Mathey DG, Siegert R, Bleifeld W. Left ventricular relaxation and filling pattern in different forms of left ventricular hypertrophy: an echocardiographic study. Am J Cardiol 1980; 45: 15-23.

8 Dreslinski GR, Frohlich ED, Dunn FG, Messerli FH, Suarez DH, Reisin E. Echocardiographic diastolic ventricular abnormality in hypertensive heart disease: atrial emptying index. Am $\mathcal{f}$ Cardiol 1981; 47: 1087-90.

9 Messerli FH, Glade LB, Elizardi DG, Dreslinski GR, Dunn FG, Frohlich ED. Cardiac rhythm, arterial pressure, and urinary catecholamines in hypertension with and without left ventricular hypertrophy [Abstract]. Am f Cardiol 1981; 47: 480.

10 Stone PH, Antman EM, Muller JE. Braunwald E. Calcium channel blocking agents in the treatment of cardiovascular disorders. Part II: Hemodynamic effects and clinical applications. Ann Intern Med 1980; 93: 886-904.

11 Salcedo EE, Gockowski K, Tarazi RC. Left ventricular mass and wall thickness in hypertension. Comparison of $M$-mode and two-dimensional echocardiography in two experimental models. Am f Cardiol 1979; 44: 936-40.

12 Cohen A, Hagan AD, Watkins J, et al. Clinical correlates in hypertensive patients with left ventricular hypertrophy diagnosed with echocardiography. Am $\mathcal{J}$ Cardiol 1981; 47: 335-41.

13 Grossman W, Jones D, McLaurin LP. Wall stress and patterns of hypertrophy in the human left ventricle. $\mathcal{F}$ Clin Invest 1975; 56: 56-64.

14 Reichek N, Wilson J, Sutton MSJ, Plappert TA, Goldberg S, Hirshfeld JW. Noninvasive determination of left ventricular end-systolic stress: validation of the method and initial application. Circulation 1982; 65: 99-108.

15 Sandler H, Dodge HT. Left ventricular tension and stress in man. Circ Res 1963; 13: 91-104.

16 Ratshin RA, Rackley CE, Russell RO Jr. Determination of left ventricular preload and afterload by quantitative echocardiography in man. Circ Res 1974 ; 34: 711-8.

17 Weber KT, Janicki JS, Hefner LL. Left ventricular force-length relations of isovolumic and ejecting contractions. Am $\mathcal{F}$ Physiol 1976; 231: 337-43.

18 Grossman W, Braunwald E, Mann T, McLaurin LP, Green LH. Contractile state of the left ventricle in man as evaluated from end-systolic pressure-volume relations. Circulation 1977; 56: 845-52.

19 Guazzi M, Fiorentini C, Olivari MT, Polese A. Cardiac load and function in hypertension. Ultrasonic and hemodynamic study. Am $\mathcal{F}$ Cardiol 1979; 44: 1007-12.

20 Sannerstedt R, Julius S, Conway J. Hemodynamic responses to tilt and beta-adrenergic blockade in young patients with borderline hypertension. Circulation 1970; 42: 1057-64.

21 Lederballe Pedersen 0 . Calcium blockade as a therapeutic principle in arterial hypertension. Acta Pharmacol Toxicol (Kbh) 1981; 49 (suppl 2): 5-31.

22 Midtbo K, Hals O. Verapamil in the treatment of hypertension. Current Therapeutic Research 1980; 27: 830-8.

23 Boullin DJ. The action of extracellular cations on the release of the sympathetic transmitter from peripheral nerves. F Physiol (Lond) 1967; 189: 85-99.

24 Olivari MT, Bartorelli C, Polese A, Fiorentini C, Moruzzi P, Guazzi MD. Treatment of hypertension with nifedipine, a calcium antagonistic agent. Circulation 1979; 59: 1056-62.

25 Tarazi RC, Miller A, Frohlich ED, Dustan HP. Electrocardiographic changes reflecting left atrial abnormality in hypertension. Circulation 1966; 34: 818-22.

26 Antman E, Stone PH, Muller JE, Braunwald E. Calcium channel blocking agents in the treatment of cardiovascular disorders. Part I: Basic and clinical electrophysiologic effects. Ann Intern Med 1980; 93: 875-85.

27 Chew CYC, Hecht HS, Collett JT, McAllister RG, Singh $B N$. Influence of severity of ventricular dysfunction on hemodynamic responses to intravenously administered verapamil in ischemic heart disease. Am $\mathcal{f}$ Cardiol 1981; 47: 917-22.

Requests for reprints to Professor Maurizio D Guazzi, Istituto Ricerche Cardiovascolari, Via Bonfadini 214, 20138 Milano, Italy. 